\section{Phycology and physiology}

Algal Physiology and Biochemistry. Edited by W. D. P. Stewart. (Botanical Monographs, vol. 10.) Pp. xi+989. (Blackwell Scientific: Oxford and London, 1974.) $£ 15.50$.

Much basic physiological and biochemical information on plants comes from the study of algae, and the general plant physiologist will be interested in this book as a summary of current knowledge on algal chemistry and function. The phycologist's requirement is also for a clear statement of the algal situation, together with a brief setting of the general scene so that cross comparisons can be made for major groups within the algae and between algae and other plants. That format is adopted by most of the authors contributing to this book, usually with marked success.

The book begins with a sensible comment on biochemical taxonomy, appropriately enough by R. A. Lewin who edited the 1962 Physiology and Biochemistry of Algae, now superseded by the present volume except as a survey of the earlier literature; I am glad to see Dr Lewin warn against the dangers of generalising from studies on one strain of one species under one set of conditions, and of making comparisons at class level from knowledge of a few species out of thousands. This is followed by comprehensive chapters on cell walls and polysaccharides, storage products, fatty acids and lipids, sterols and nucleic acids. Each contains a wealth of information correlated to the biology and taxonomic position of the algae concerned. In a chapter on nuclear and cytoplasmic inheritance in green algae, Ruth Sager confines her account almost exclusively to investigations on Chlamydomonas. The result is a chapter of substance by the expert in the field and, since a forthcoming title in the Botanical Monographs series is a 250 page book on The Genetics of Algae, Dr Sager is obviously right to present this account rather than a telegraphic review of all algal genetics.

Unfortunately, one or two chapters attempt to summarise overlarge topics and fail for lack of space. In the chapter on cytoplasmic organelles, L. V. Evans tries to review the relationship between the structure and function of f 1 a g e lla, haptonemata, trichocysts, scales, lysosomes, microbodies, contractile vacuoles, walls, nuclei, microtubules, nuclear division, mitochondria and Golgi bodies, all in less than 20 pages of text. The task is manifestly impossible and the result is a catalogue of truncated descriptions and oversimplified generalisations that seem out of key with the rest of the book. Three pages are devoted to descriptions of mitotic ultrastructure in various algae but there is no comment on significance, either functional or phylogenetic. Golgi structure and function receive better treatment but it is a pity that a separate chapter could not have been given to this topic, allowing room for

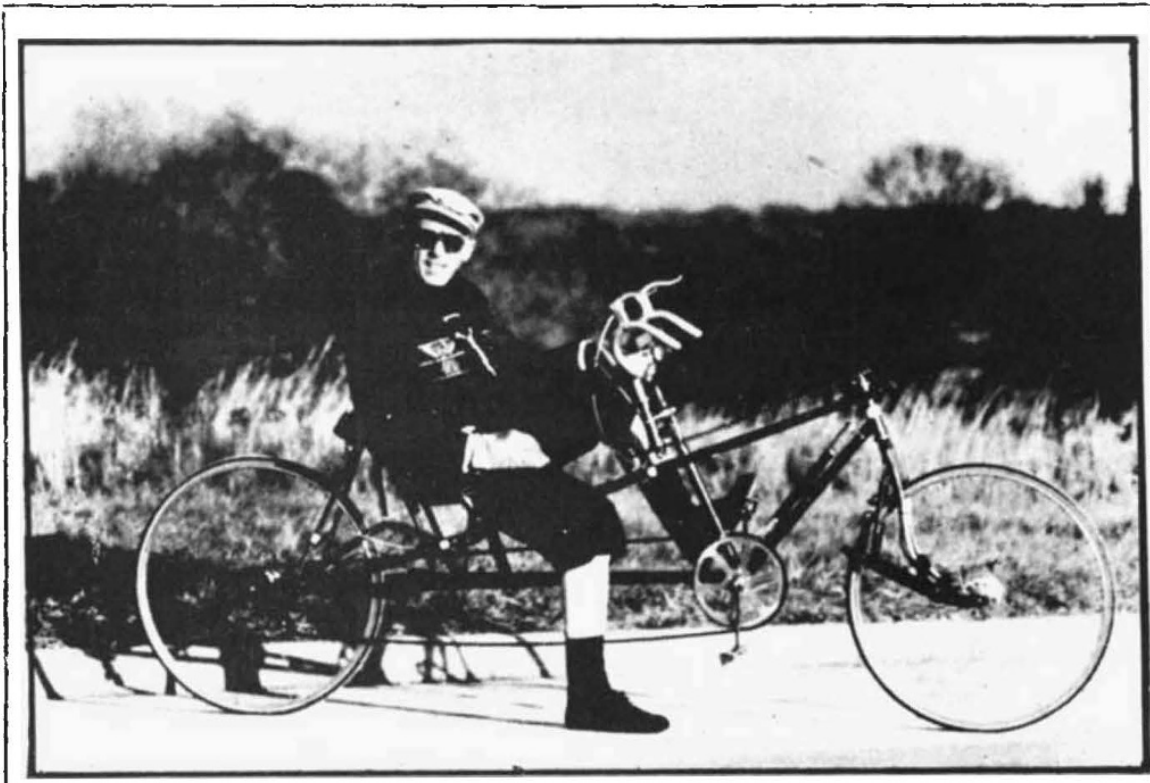

Captain Dan Henry, supine upon his recumbent bicycle. Captain Henry, from Flushing. New York, became well known for his early design of sprung bicycle. His adaptation, though somewhat cumbersome by today's standards, rendered his machine "faster in hill climbing", and he was able to note with some satisfaction that his tyres lasted longer. Energy conservationists take note. From Bicycling Science. Ergonomicy and Mechanics. By Frank Rowland Whitt and David Gordon Wilson. Pp. xiii +247. (MIT Press: Cambridge, Massachusetts, and London, 1974.) n.p. some interpretation and ideas in the account of other organelles. Plastids are given a whole chapter in which $T$. Bisalputra is able to discuss, albeit briefly, variations of chloroplast ultrastructure in relation to algal classes and pigments, and this is followed by chapters on chlorophylls, carotenoids and biliproteins, which satisfactorily tidy up many of the earlier conflicting and doubtful records (especially for carotenoids).

Moving from biochemical to physiological topics, we come to a series of excellent chapters on light absorption, emission and photosynthesis, photosynthetic electron flow-with a fascinating small follow-up chapter on the elucidation of the electron transport chain by the study of algal mutants-and a wide range of other topics. Physiologists may fight among themselves over some of the more controversial ideas expressed in these chapters but personally I found them, not surprisingly, highly informative and, more surprisingly for a nonphysiologist, largely intelligible. In cases where the technical aspects of the subject are difficult or, frankly, beyond me, I still found that most of the authors were able to convey to me the general significance of the studies under discussion.

In a short review one can do little more than indicate the main coverage of the book and comment on its general standard. The coverage is wide, the general standard excellent. If there are any significant errors of chemical fact these will doubtless be commented on in other reviews by biochemists. There is a discrepancy between Evans (pp. 96-7) and Nultsch (p. 866) in the information on microtubule subunits, even allowing for the fact that $4.5 \mu \mathrm{m}$ is a misprint for $4.5 \mathrm{~nm}$ in the latter account; Prasinophyceae are characterised by scaly flagella rather than hairy flagella (p. 3); other errors and misprints are few and far between. Production is good, though some of the electron micrographs are overenlarged, badly printed and chopped off at the edges. The price is high, but that is to be expected for a 1974 book of nearly 1,000 pages.

As a nonphysiological, nonbiochemical phycologist, I found some parts of this book easy and enjoyable to read and other parts heavy going. In relation to my research, teaching, reading and editing interests in the algae, the book has already proved informative and stimulating. The data summaries, formulae, tables and discussions will be invaluable for reference purposes. There is no doubt that this book will be an essential work of reference for years to come, both for the phycologist and the plant physiologist. Gordon F. Leedale 